\title{
MECHANICAL PROPERTIES OF NYLON PARTS PRODUCED BY FUSED DEPOSITION MODELING
}

\author{
Sabit Hasçelik, Ömer T. Öztürk, Sezer Özerinç \\ Department of Mechanical Engineering, Middle East Technical University, Ankara, 06800 Turkey \\ Corresponding author: Sezer Özerinç, ozerinc@metu.edu.tr
}

\begin{abstract}
Fused deposition modeling (FDM) is a widely used additive manufacturing technique for producing polymeric parts. While most commonly used FDM filaments are PLA and ABS, nylon is a widely used thermoplastic polymer in industry. This study investigated the mechanical properties of FDMproduced specimens made of nylon and quantified the effect of process parameters such as raster orientation and nozzle temperature on the mechanical properties. As the nozzle temperature increases, specimens become stronger with higher elongations at the break. This is mainly due to the improved fusion between the layers, provided by an expansion of the heat-affected zone. On the other hand, specimens with diagonal raster orientation exhibit higher elongations than those with perpendicular and parallel raster. The findings also emphasize the synergistic effects between nozzle temperature and printing orientation, showing that optimization should consider the two parameters together. Overall, FDM can produce strong nylon parts with adequate ductility suitable for load-bearing applications. However, achieving such results requires a detailed optimization of process parameters.
\end{abstract}

Key words: Fused Deposition Modeling, Additive Manufacturing, Nylon, Polyamide, Mechanical Properties.

\section{INTRODUCTION}

Additive manufacturing (AM) is a technology that allows the generation of three-dimensional objects from a CAD model through the increase of cohesion without employing any formative or subtractive operation. The unique capability of AM in producing complicated shapes is beneficial for various applications of transportation, biomedical, and energy industries [1]. Furthermore, the versatility of the technique allows the quick and effective production of custom parts for consumer products and the manufacturing of prototypes for design iterations [2].

AM is applicable to a wide range of materials, including metals, ceramics, and polymers. AM of polymers employs several different techniques developed over the years, such as selective laser sintering (SLS), stereo-lithography (SLA), digital light processing (DLP), and fused deposition modeling (FDM). While most techniques are based on the layer-by-layer production approach, the layering methodology and the means of establishing fusion can differ.

Fused deposition modeling (FDM) is a costeffective alternative among available polymer AM techniques. Figure 1 shows a schematic view of the FDM process. The method employs a heated nozzle that melts and extrudes the polymer in the desired trajectory through the motion of the nozzle in the $\mathrm{x}-\mathrm{y}$ plane. After completing the printing of a layer, the printing stage goes down over a layer thickness, and the process repeats until all layers are complete.

The working principle of FDM requires that the raw polymer is thermoplastic. Most commonly used FDM materials include polylactic acid (PLA), acrylonitrile butadiene styrene (ABS), polyethylene terephthalate (PET), and polyamide (nylon). The method exhibits many essential process parameters such as raster orientation, infill ratio, build orientation, and nozzle temperature, which strongly influence the mechanical properties of the produced part [3].

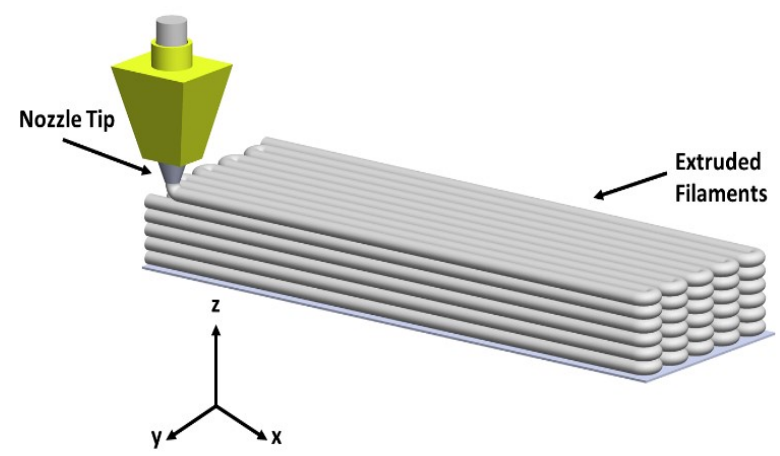

Fig. 1. A schematic representation of the FDM process

Nylon is one of the most widely used polymers in the industry, with an annual consumption of almost 9 million tons in 2020 [4]. Nylon's high strength, 
durability, and high wear resistance make it useful for many applications $[5,6]$. This study investigates the mechanical properties of nylon parts produced by FDM, focusing on understanding the effect of process parameters on mechanical performance. The findings clarify the feasibility of nylon as an FDM material to produce load-bearing parts and structures.

\section{EXPERIMENTAL DETAILS}

An Ultimaker 2+ 3D printer printed the nylon specimens according to ASTM D638 Standard Test Method for Tensile Properties of Plastics [7] (see Figure 2. The raw material used was a commercially available Ultrafuse polyamide filament (BASF, Germany) with a diameter of $2.85 \mathrm{~mm}$. Table 1 shows printing parameters that are the same for each specimen. A 3D printing tape ensured the proper adhesion of the specimen on the printing stage. The shell consisted of a single line, and the top and bottom layers employed a single layer each to observe the effect of raster orientation more clearly.

A Zwick/Roell Z250 universal testing machine performed the mechanical tests with a $5 \mathrm{~mm} / \mathrm{min}$ linear displacement rate. For each process parameter combination, five identical specimens were printed and tested to obtain statistically significant results. An Ultima IV diffractometer performed X-ray diffraction over a $2 \theta$ range of $5^{\circ}$ to $80^{\circ}$ with a scanning speed of $1 \%$ min used for data acquisition.

Table 1. FDM parameters used in the study

\begin{tabular}{|c|c|c|}
\hline Parameters & Unit & Values \\
\hline Number of Top and Bottom & & \\
Layers & - & 1 \\
Number of Shell Lines & - & 1 \\
Infill Ratio & $\%$ & 100 \\
Layer Height & $\mathrm{mm}$ & 0.2 \\
Printing Speed & $\mathrm{mm} / \mathrm{s}$ & 45 \\
Bed Temperature & $\left({ }^{\circ} \mathrm{C}\right)$ & 80 \\
Filament Diameter & $\mathrm{mm}$ & 2.85 \\
Nozzle Diameter & $\mathrm{mm}$ & 0.4 \\
\hline
\end{tabular}

The study aimed to show the effects of raster orientation and nozzle temperature on mechanical properties. Table 2 shows a summary of the parameters investigated. The nozzle temperature varied between $235^{\circ} \mathrm{C}$ and $260^{\circ} \mathrm{C}$, and for each nozzle temperature, several raster orientations were considered.
Table 2. Design of experiments and the associated printing parameters

\begin{tabular}{|c|c|c|c|c|}
\hline Parameter & \multicolumn{4}{|c|}{ Values } \\
\hline $\begin{array}{c}\text { Nozzle Temperature } \\
\left({ }^{\circ} \mathrm{C}\right)\end{array}$ & 235 & 240 & 250 & 260 \\
\hline $\begin{array}{c}\text { Raster Orientation } \\
\left({ }^{\circ}\right)\end{array}$ & \pm 45 & $\begin{array}{c} \pm 45 \\
0\end{array}$ & $\begin{array}{c}0 \\
90\end{array}$ & $\begin{array}{c} \pm 45 \\
0\end{array}$ \\
\hline
\end{tabular}

Raster orientation defines the trajectory of the nozzle with respect to the loading axis of the specimen, as described in Figure 2. We considered three cases, namely, diagonal $\left( \pm 45^{\circ}\right)$, perpendicular $\left(90^{\circ}\right)$, and parallel $\left(0^{\circ}\right)$. The diagonal case employed alternating directions in every other layer, as demonstrated in Figure 2(a). While the images show some spacing between the printed lines for clarity, actual specimens employed $100 \%$ infill for each case.

(a)

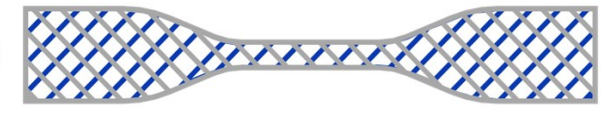

(b)

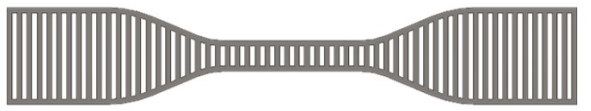

(c)

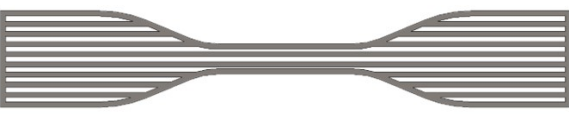

(d)

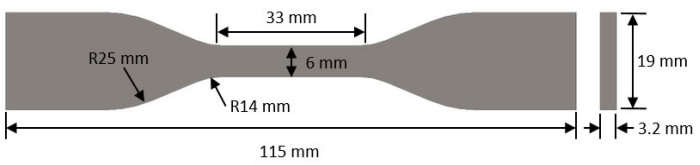

Fig. 2. Schematic representation of raster orientations. (a) Diagonal $\left( \pm 45^{\circ}\right)$, (b) Perpendicular $\left(90^{\circ}\right)$, (c) Parallel $\left(0^{\circ}\right)$.

(d) Dimensions of the specimens according to ASTM D638 - Type IV

\section{RESULTS AND DISCUSSION}

Figure 3 shows the XRD data for a range of nozzle temperatures for specimens printed with diagonal raster. In the data, intensity values are shifted by a constant value for clarity. The results indicate that the nozzle temperature does not have a remarkable effect on the spectra. The relatively broad peaks suggest a semicrystalline structure, in agreement with the general characteristic of polyamide [8].

Figure 4(a) shows stress-strain curves of specimens printed at $260^{\circ} \mathrm{C}$ with $0^{\circ}$ raster orientation. The good agreement between individual tests indicates the high repeatability of the printing and the testing. Figure 4(b) shows example stress-strain curves as a function of nozzle temperature for the raster orientation of $\pm 45^{\circ}$. The results demonstrate a monotonic increase in strength and elongation at 
break with increasing nozzle temperature. The nozzle temperature of $260^{\circ} \mathrm{C}$ provides the best results, with an elongation at break exceeding $200 \%$, which is considerably higher than conventionally produced polyamide specimens [3].

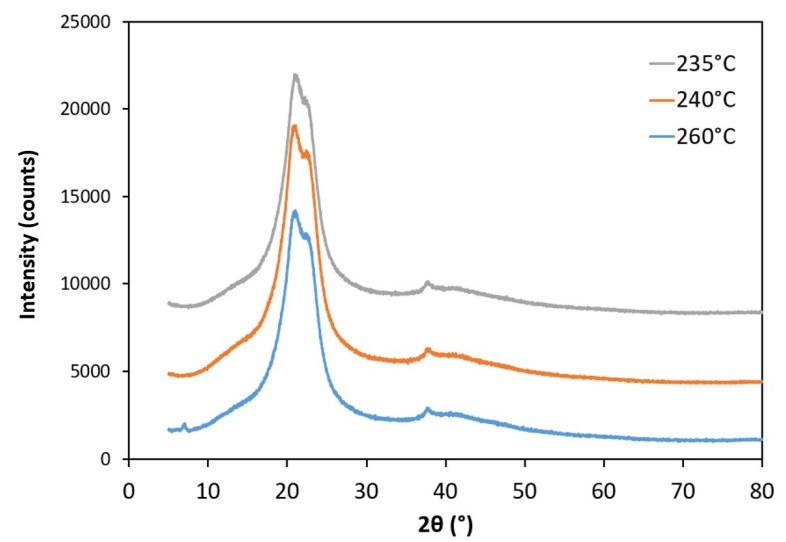

Fig. 3. XRD results of specimens printed at a range of nozzle temperatures
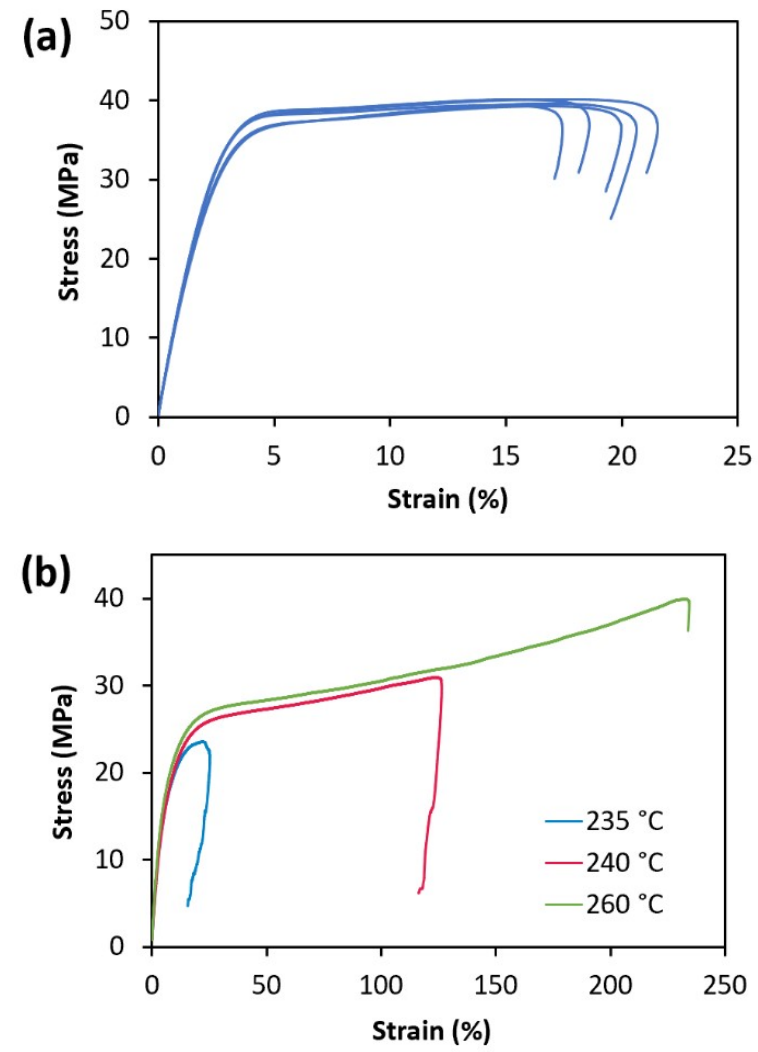

Fig. 4. (a) Stress-strain curves for $0^{\circ}$ raster and $260^{\circ} \mathrm{C}$ nozzle temperature. (b) Example stress-strain curves for each nozzle temperature for the case of $\pm 45^{\circ}$ raster orientation

Figure 5 shows example stress-strain curves corresponding to three different raster orientations for the case of $260^{\circ} \mathrm{C}$ nozzle temperature. The results demonstrate that there is a dramatic effect of raster orientation on the mechanical properties. A relatively high is observed for the case of the parallel raster, in agreement with previous studies on FDM-produced parts [9]. This behavior is mainly due to the high loadcarrying capacity provided by the continuous line of deposited polymer in the direction of loading.

On the other hand, the elongation at break exhibits an unusual trend. The lowest ductility is observed for the case of the parallel raster in this study, which tends to provide the highest elongation values in the literature $[10,11]$. Our results indicate that the diagonal raster provides the highest ductility, and the perpendicular raster lies in between these two extremes.

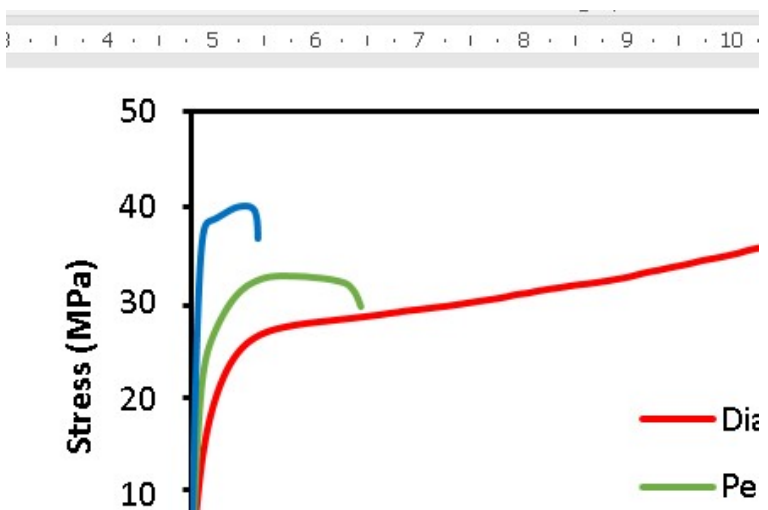

Fig. 5. Representative stress-strain curves for different raster orientations of diagonal $\left( \pm 45^{\circ}\right)$, perpendicular $\left(90^{\circ}\right)$, and parallel $\left(0^{\circ}\right)$

Figure 6 shows the photographs of the respective specimens after testing, in line with the stress-strain data. All specimens in the figure were printed by using a nozzle temperature of $260^{\circ} \mathrm{C}$. A careful observation of the parallel raster specimens indicates that the failure is close to the grip regions of the gauge section. This might indicate a stress concentration effect due to the unique printing trajectory of the associated case.

(a)

(b)

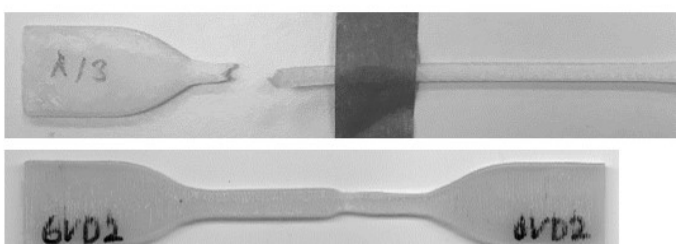

Fig. 6. Post-testing photographs of representative specimens corresponding to different raster orientations. a) Diagonal raster $\left( \pm 45^{\circ}\right)$, b) Perpendicular raster $\left.\left(90^{\circ}\right), \mathrm{c}\right)$ Parallel raster $\left(0^{\circ}\right)$

Figure 7 and Table 3 summarize the results for all combinations of nozzle temperatures and raster orientations considered in this study. Figure 7(a) and (b) show the results of the ultimate tensile strength (UTS) and elastic modulus, respectively. An increase in the nozzle temperature improves UTS in every 
case of raster orientation. This is mainly due to the increase in the temperature and width of the heataffected zone, which establishes superior fusion between the printed lines and layers.

On the other hand, the extent of improvement by changing the nozzle temperature depends on the raster orientation. The highest sensitivity to nozzle temperature is observed for the case of the diagonal raster, and for the perpendicular raster, the effect becomes less pronounced. For the case of $260^{\circ} \mathrm{C}$, the strength values of parallel and diagonal raster are virtually the same, suggesting that an ideal level of fusion has been established between the printing lines.

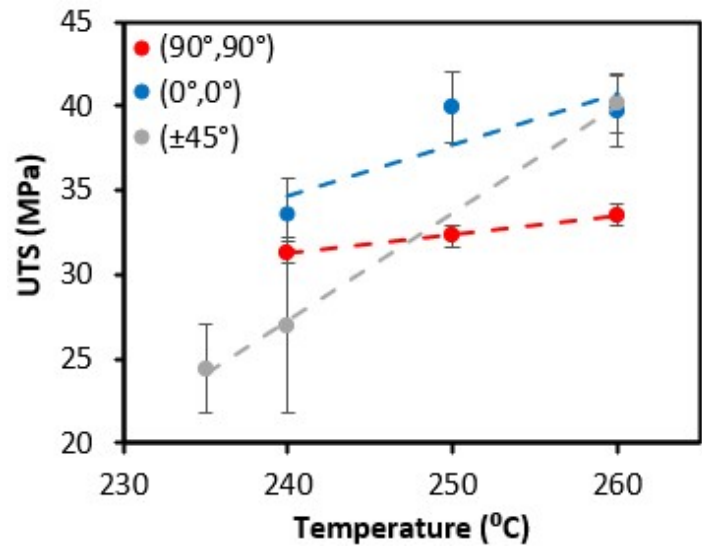

(a)

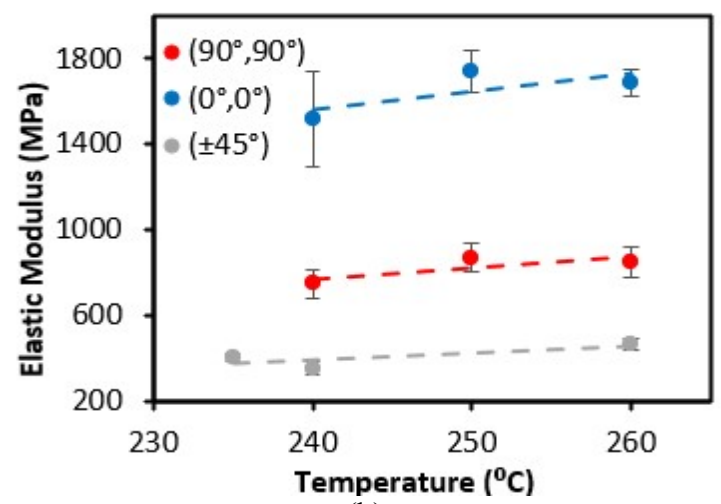

(b)

Fig. 7. (a) UTS variations as a function of nozzle temperature and raster orientation. (b) Elastic modulus variations as a function of nozzle temperature and raster orientations

Table 3. Summary of mechanical testing data

\begin{tabular}{|c|c|c|c|}
\hline $\begin{array}{c}\text { Raster } \\
\text { Orientation }\end{array}$ & $\begin{array}{c}\text { Nozzle } \\
\text { Temperature } \\
\left({ }^{\circ} \mathrm{C}\right)\end{array}$ & $\begin{array}{c}\text { UTS } \\
(\mathrm{MPa})\end{array}$ & $\begin{array}{c}\text { UTS St. } \\
\text { Dev. (MPa) }\end{array}$ \\
\hline $\pm 45^{\circ}$ & 235 & 24.4 & 2.7 \\
$\pm 45^{\circ}$ & 240 & 27.0 & 5.2 \\
$\pm 45^{\circ}$ & 260 & 40.2 & 1.8 \\
$90^{\circ}$ & 240 & 31.3 & 0.73 \\
$90^{\circ}$ & 250 & 32.3 & 0.52 \\
$90^{\circ}$ & 260 & 33.5 & 0.94 \\
$0^{\circ}$ & 240 & 33.6 & 2.3 \\
$0^{\circ}$ & 250 & 39.9 & 0.46 \\
$0^{\circ}$ & 260 & 39.7 & 0.40 \\
\hline
\end{tabular}

\begin{tabular}{|c|c|c|c|}
\hline $\begin{array}{c}\text { Elastic } \\
\text { Modulus } \\
(\mathrm{MPa})\end{array}$ & $\begin{array}{c}\text { Elastic } \\
\text { Modulus St. } \\
\text { Dev. (MPa) }\end{array}$ & $\begin{array}{c}\text { Elongation } \\
(\%)\end{array}$ & $\begin{array}{c}\text { Elongation } \\
\text { St. Dev. (\%) }\end{array}$ \\
\hline 403 & 16 & 22.9 & 7.2 \\
354 & 31 & 83.1 & 59 \\
467 & 26 & 235 & 15 \\
749 & 65 & 23.4 & 2.9 \\
869 & 66 & 37.2 & 20 \\
849 & 70 & 70.2 & 58 \\
1518 & 221 & 12.1 & 3.1 \\
1739 & 96 & 19.3 & 0.46 \\
1685 & 63 & 16.0 & 1.2 \\
\hline
\end{tabular}

The effect of raster orientation can also change dramatically with temperature. For the case of $260^{\circ} \mathrm{C}$, the highest UTS is achieved for diagonal raster. On the other hand, the same orientation results in the lowest UTS for the case of $240^{\circ} \mathrm{C}$. The results suggest that there is a synergistic interaction between nozzle temperature and raster orientation. The samples with higher elongations at break tend to have more pronounced UTS values due to the positive slope of the stress-strain curve, which makes the problem even more complicated.

Compared to the UTS trends, elastic modulus shows a minor variation with nozzle temperature. On the other hand, the raster orientation has a significant influence on the elastic modulus. The highest modulus is observed for the case of the parallel raster, and the diagonal raster exhibits the lowest modulus. The high stiffness of the parallel raster can be explained by the strong and continuous lines of polymer along the loading direction. In the case of perpendicular and diagonal raster, the weaker interfaces experiencing tensile loading increase the compliance of the specimens.

\section{CONCLUSIONS}

This study investigated the mechanical properties of nylon parts produced by fused deposition modeling (FDM). The results show that FDM nozzle temperature and raster orientation are critical parameters that directly influence the mechanical properties. The most desirable results were obtained for the highest nozzle temperatures combined with the diagonal raster.

The results demonstrate that FDM can produce strong and relatively ductile nylon parts suitable for loadbearing applications. However, the selection of process parameters should be made carefully to ensure optimum performance.

\section{ACKNOWLEDGMENTS}

This project was supported by the undergraduate research program AdımODTÜ by Middle East Technical University. We thank METU Central 
Laboratory facilities for their help in the materials testing.

\section{REFERENCES}

1. Ngo TD, Kashani A, Imbalzano G, Nguyen KTQ, Hui D. (2018). Additive manufacturing (3D printing): $A$ review of materials, methods, applications and challenges. Composites Part B: Engineering; 143, 172-196.

https://doi.org/10.1016/j.compositesb.2018.02.012.

2. Campbell I, Bourell D, Gibson I. (2012). Additive manufacturing: rapid prototyping comes of age. Rapid Prototyping Journal, 18, 255-258, https://doi.org/10.1108/13552541211231563.

3. Bakır AA, Atik R, Özerinç S. (2021), Mechanical properties of thermoplastic parts produced by fused deposition modeling:a review. Rapid Prototyping Journal; 27, 537-561, https://doi.org/10.1108/RPJ03-2020-0061.

4. Nylon - Global Market Trajectory \& Analytics. Global Industry Analysts, Inc; 2021.

5. Senthilvelan S, Gnanamoorthy R. (2006), Fiber Reinforcement in Injection Molded Nylon 6/6 Spur Gears. Appl Compos Mater, 13, 237-248. https://doi.org/10.1007/s10443-006-9016-9.

6. Gong X, Chen X, Zhou Y., (2017), Advanced weaving technologies for high-performance fabrics.

7. ASTM D638 - 14 Standard Test Method for Tensile Properties of Plastics (2017).

8. Abhilash V, Rajender N, Suresh K. (2016), Chapter 14 - X-ray diffraction spectroscopy of polymer nanocomposites. In: Thomas S, Rouxel D, Ponnamma D, editors. Spectroscopy of Polymer Nanocomposites, William Andrew Publishing, p. 410-451. https://doi.org/10.1016/B978-0-323-401838.00014-8.

9. Casavola C, Cazzato A, Moramarco V, Pappalettere C. (2016), Orthotropic mechanical properties of fused deposition modelling parts described by classical laminate theory. Materials \& Design, 90, 453-458. https://doi.org/10.1016/j.matdes.2015.11.009.

10. Riddick JC, Haile MA, Wahlde RV, Cole DP, Bamiduro O, Johnson TE. (2016), Fractographic analysis of tensile failure of acrylonitrile-butadienestyrene fabricated by fused deposition modeling. Additive Manufacturing, 11, 49-59. https://doi.org/10.1016/j.addma.2016.03.007.

11. Liu H, He H, Peng X, Huang B, Li J. (2019). Three-dimensional printing of poly(lactic acid) biobased composites with sugarcane bagasse fiber: Effect of printing orientation on tensile performance. Polymers for Advanced Technologies; 30, 910-922. https://doi.org/10.1002/pat.4524.
Received: July 25, 2021 / Accepted: December 15, 2021 / Paper available online: December 20, 2021 (C) International Journal of Modern Manufacturing Technologies 